\title{
A Qualitative Comparison of Unsteady Operated Compressor Stator Cascades with Active Flow Control
}

\author{
Marcel Staats, Jan Mihalyovics and Dieter Peitsch
}

\begin{abstract}
Currently, the influence and scaling of active flow control by means of pulsed jet actuators applied to a two-dimensional compressor cascade flow are well understood. However, the presence of a transverse pressure gradient in a 3D annular cascade configuration causes additional effects which need a more profound consideration. The objective of this study is to compare results from the linear cascade setup to the annular one and transfer the AFC technology respectively.
\end{abstract}

Keywords Compressor cascade $\cdot$ Active flow control $\cdot$ Experiment Flow mapping $\cdot$ Flow visualization $\cdot$ Pulsed jets

\section{Introduction}

Improving the overall efficiency of a gas turbine has always been an objective for researchers. One promising possibility is the implementation of a constant volume combustion $(C V C)$. Stathopoulus et al. [1] report a potential efficiency increase of up to $20 \%$ when passing from the Joule to the Humphrey cycle. Beneficial effects with respect to the efficiency are also reported by Schmidt and Staudacher [2] when introducing the $C V C$ cycle. A pressure gain combustion may be envisioned utilizing a pulse detonation combustor $(P D C)$. One way of implementing a $P D C$ into a gas turbine is the use of multiple combustion tubes arranged in an annular pattern that close subsequently whenever combustion takes place [3]. Such tubes are opened and

\footnotetext{
M. Staats $(\varangle) \cdot$ J. Mihalyovics $(\varangle) \cdot$ D. Peitsch

Technische Universität Berlin, Institute of Aeronautics and Astronautics,

Chair for Aerodynamics, D-10587 Berlin, Germany

e-mail: Marcel.Staats@tu-berlin.de

J. Mihalyovics

e-mail: Jan.Mihalyovics@tu-berlin.de 
refilled with fresh gaseous air-fuel mixture and then closed for ignition. Multiple tubes would be operated in a pulse detonation engine $(P D E)$, introducing strong unsteady effects to all turbomachinery components $[4,5]$.

In a turbocharged $P D E$, the compressor will specially suffer from disturbances originating from the $P D C$ combustion tubes. In a worst case configuration, the combustion tubes are installed very closely downstream of the last compressor stator without providing a plenum. This configuration would surely be beneficial for the overall length of the gas turbine or aero engine but also maximizes the intermittent pressure fluctuations to the compressor caused by the $P D C$. Investigations on the unsteady flow-field that would be expected under the regime of pressure gaining combustion show severe flow separation phenomena occurring on the compressor stator [6].

These unsteady three-dimensional flows enhance secondary flow structures such as the corner vortex and possible flow separation. Indeed, it has been proven that the highest pressure losses occur specifically within these regions of separated flow [7, 8]. Within this framework, Gbadebo et al. [9] showed that the size and the characteristics of the corner vortices are remarkably increased by periodic blade incidence changes, which can also be associated with a $P D C$.

Therefore, some type of flow control is required to ensure the aerodynamic operability, especially for such unsteady types of gas turbines. Active flow control (AFC) opportunities for compressor stators were investigated in [10-14]. Research indicated that pulsed jet actuators ( $P J A)$ are more effective for $A F C$ application compared to steady blowing actuators, as shown by Seifert [15] and Hecklau et al. [16]. The feasibility of suppression of periodic flow separation phenomena in a unsteady operated compressor stator cascade using PJA was shown by Staats et al. [17]. Further research regarding unsteady compressor flows was done by Steinberg et al. [18, 19]. Here emphasis was given to apply iterative learning control to an unsteady compressor stator flow-field.

The objective of this work is the transfer of the technology of a two dimensional cascade setup (linear cascade) to a three dimensional setup (annular cascade). The research work emphasizes the qualitative comparability of the two configurations, as the geometric characteristics have mostly been transferred to the annular setup. Furthermore, results with active flow control (using PJA) in the annular test setup are compared to the linear compressor test setup. The qualitative comparison of the results showed good consistency among the two test setups.

\section{Experimental Setup}

In this contribution, results conducted at two separate compressor stator test rigs are presented. Both experiments, the linear- and annular cascade, were equipped with identical highly loaded controlled diffusion airfoils $(C D A)$ and operated at a chordlength based REYNOLDS-number of $R e=6 \times 10^{5}$. The blades had a design flow 


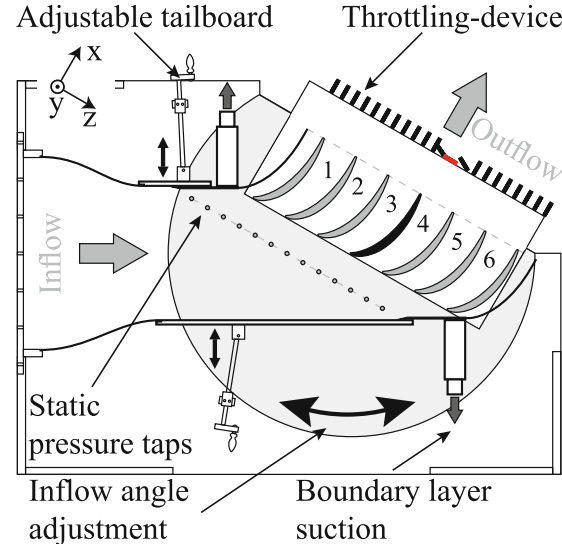

(a) $2 \mathrm{D}$ cascade test section

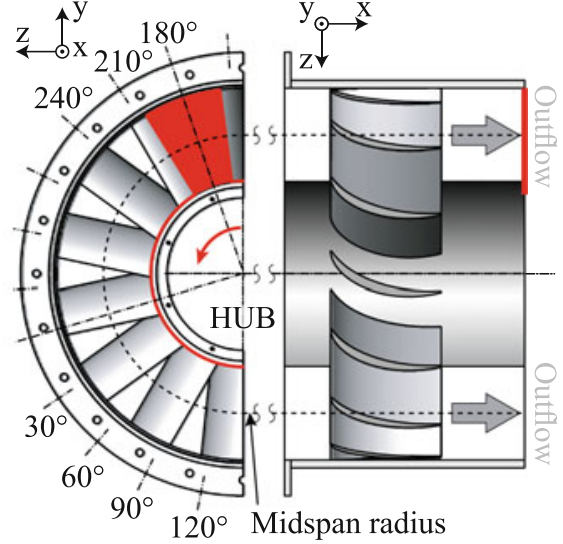

(b) $3 \mathrm{D}$ cascade test section

Fig. 1 Experimental setup for both cascade test setups (linear- and annular cascade)

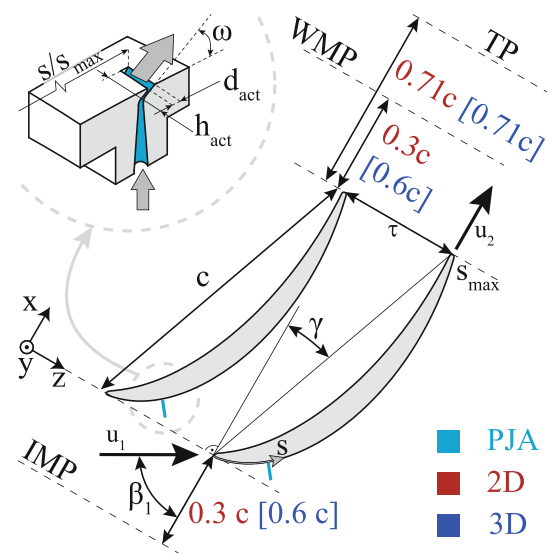

(a) 2D and 3D cascade blade geometry

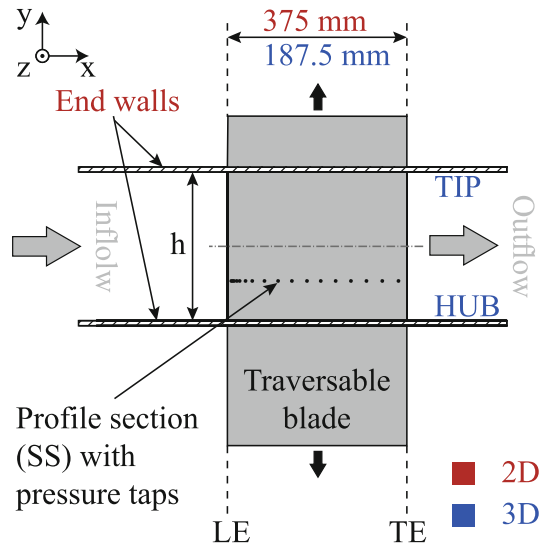

(b) Sketch of a moveable blade used in the $2 \mathrm{D}$ and $3 \mathrm{D}$ cascade

Fig. 2 Blade geometry for both cascade test setups (linear- and annular cascade)

turning angle of $\Delta \beta=60^{\circ}$ and were arranged in an airfoil stagger angle of $\gamma=20^{\circ}$. The two test sections used for the experiments are depicted in Fig. 1a and b.

Furthermore, throttling-devices were installed in both configurations that simulate the periodic unsteady effect, similar to the one expected when operating a pulse detonation combustor $(P D C)$ downstream the last compressor stator stage. In both cases, these devices were mounted in the throttling plane $(T P)$, located $0.71 \cdot c$ downstream of the compressor blades trailing edges $(T E)$. Due to a geometric scaling in the cascade designs the dimensionless frequency (STROUHAL-number $S t$ ) is introduced 
Table 1 Geometric data of the linear (2D) and the annular (3D) compressor cascade

\begin{tabular}{l|l|l|l}
\hline Name & Parameter & $2 \mathrm{D}_{c}$ & $3 \mathrm{D}_{c}$ \\
\hline Stator blade count & $n$ & 7 & 15 \\
\hline Stator height & $h$ & $300 \mathrm{~mm}$ & $150 \mathrm{~mm}$ \\
\hline Stator chord length & $c$ & $375 \mathrm{~mm}$ & $187.5 \mathrm{~mm}$ \\
\hline Total length of SS & $s_{\max }$ & $420 \mathrm{~mm}$ & $210 \mathrm{~mm}$ \\
\hline Stator turning & $\Delta \beta$ & $60^{\circ}$ & $60^{\circ}$ \\
\hline Stagger angle & $\gamma$ & $20^{\circ}$ & $20^{\circ}$ \\
\hline Hub to tip ratio & $y_{H} / y_{T}$ & - & 0.5 \\
\hline $\begin{array}{l}\text { Pitch to chord ratio } \\
\text { midspan }\end{array}$ & $\tau / c$ & 0.4 & 0.5 \\
\hline De Haller & $u_{2} / u_{1}$ & 0.5 & 0.5 \\
\hline
\end{tabular}

that corresponds to the frequency $(f)$ the throttling devices are operated with. It is calculated as follows:

$$
S t_{\text {throttling }}=\frac{f_{\text {throttling }} \cdot c}{u_{1}},
$$

where $f_{\text {throtting }}$ is the throttling frequency, $c$ is the blade chord length and $u_{1}$ is the freestream velocity at the inlet of the cascade. The operational limit of the throttling device of the linear cascade is $S t=0.0525\left(f_{\text {throttling,linear }}=3.5 \mathrm{~Hz}\right)$, whereas the annular cascade provides the periodic disturbance using a rotating disk, equipped with two paddles. Thus, higher throttling frequencies can be reached. In this case, the limit is $S t=0.06$ ( $f_{\text {throttling,linear }}=16.0 \mathrm{~Hz}$ ). In the experiments discussed in this paper, the throttling STROUHAL-number was kept constant at $S t_{\text {throtting }}=0.03$. The geometric configuration of the stator passages is given in Figure $2 \mathrm{a}$ and in Table 1 . The numbers printed in red color indicate the measures for the linear cascade and the data printed in blue color denote the geometry used in the annular cascade experiments. Further details on the two individual test setups are presented in the following subsections.

\subsection{Linear Cascade Setup and Instrumentation}

The linear cascade was attached to a low speed open wind tunnel facility operated at the Chair of Aerodynamics of Technische Universität Berlin (TUB) (Fig. 1a). The test section was equipped with seven compressor stator blades forming six two dimensional passages. The test section was mounted to a rotatable disk that allows for inflow angle variations ranging from $\beta_{1}=55^{\circ}$ to $\beta_{1}=65^{\circ}$. In the presented experiments within this contribution the design flow turning was used $\left(\Delta \beta=60^{\circ}\right)$. Additional geometric reference data for the linear cascade configuration are shown in Table 1. Furthermore, the test setup featured adjustable tail boards and a boundary layer suction, allowing for highly symmetric flow conditions. The inflow static 
pressure was measured at the inflow measurement position $(I M P)$ at $0.3 \cdot c$ upstream of the leading edges $(L E)$. At the operational speed $\left(u_{1}=25 \mathrm{~m} / \mathrm{s}\right)$ the turbulence level at the inflow plane was below $T u \leq 1 \%$.

The periodic disturbances were introduced by a throttling-device located at 0.71 . $c$ downstream of the $T E$ s, consisting of 21 throttling blades that were closed one after the other, blocking approx. $90 \%$ of one passage at a time. This leads to a periodic disturbance to every stator passage. The passages were choked in the sequence $4-$ $5-6-1-2-3-4-e t c$. The red shaded throttling-blade (see Fig. 1a) indicates the reference blade. Whenever this blade is closed, a new cycle starts. For such an event, a phase-angle of $\varphi=180^{\circ}$ is defined. Further details regarding the throttling device of the linear cascade are given in $[6,20]$.

\subsubsection{Instrumentation}

The suction sided surface pressure measurements on the linear cascade test rig were performed on a traversable blade that was equipped with 44 flush mounted miniature differential pressure sensors [First Sensor: HCL12X5], mounted along the suction$(S S)$ and pressure side $(P S)$ of the measurement blade (see Fig. 2b). Those pressure data were evaluated by means of the static pressure coefficient $\left(c_{p}=\frac{p_{\text {blade }}(\varphi)-p_{1}}{q_{1}}\right)$. The measurement blade was traversed from $y / h=3.33 \%$ to $y / h=96.67 \%$ in increments of $\Delta y=5 \cdot 10^{-3} \mathrm{~m}$.

Five-hole-probe measurements were performed in the wake measurement plane $(W M P)$ at $0.3 \cdot c$ downstream the TEs. Five First Sensor: HCLA12X5 (-12.5 to 12.5 mbar) differential pressure sensors were used for the investigations. The traversed grid consisted of $16 \times 15$ equidistant grid points in the $y$-z-plane. The acquired data were evaluated in terms of static pressure rise coefficient $\left(C_{p}\right.$, Eq. 2$)$ and total pressure loss coefficient ( $\zeta$, Eq. 3).

$$
\begin{gathered}
C_{p}=\frac{p_{2}(y, z, \varphi)-p_{1}}{q_{1}}, \\
\zeta=\frac{p_{t, 1}-p_{t, 2}(y, z, \varphi)}{q_{1}} .
\end{gathered}
$$

\subsection{Annular Cascade Setup and Instrumentation}

A low speed, open circuit wind tunnel operated at the flight propulsion laboratory of $T U B$ was used for the annular cascade experiments. Figure $1 \mathrm{~b}$ shows a schematic depiction of the test section, introduced by Brück et al. [21].

The diameter of the casing of the test section measures $0.6 \mathrm{~m}$. In order to create an inflow angle to the annular cascade of $\beta_{1}=60^{\circ}$ at midspan 19 variable inlet guide vanes (VIGVs) produce the swirl needed for the stator inlet conditions. 
Moreover, these $V I G V$ s provide the option of changing the incidence to the stator by $\pm 5^{\circ}$. A sketch of the profile geometry used in the 3D annular cascade is shown in Fig. 2a and is supplemented by Table 1. The axial distance between the VIGVs and the stator inlet plane measures three chord lengths to ensure for sufficient mixing of the VIGV blade wakes and thus produce a homogeneous inlet turbulence of less than $T u \leq 5.0 \%$. In the annular cascade design, the blades from the linear cascade setup were downscaled and adopted to match all stator passage features of the two test setups, such as aspect ratio of the blade, pitch to chord ratio and flow turning, at mid-span.

The application of periodically throttling of the stator passages was realized by a rotating disk mounted at a distance of $0.71 \cdot c$ downstream of the TEs of the measurement section. This rotatable disk was equipped with two paddles blocking each stator passage in a given sequence. Hence one cycle of the rotating disk blocks every passage twice. When the measurement passage is fully blocked the phase-angle $\varphi=180^{\circ}$ is reached by definition. When both paddles are at the furthest distance from the measurement passage (passage flow is least disturbed) the phase-angle is defined to be $\varphi=360^{\circ}$. Thus one full revolution of the throttling device amounts to $720^{\circ}$. The resulting positions of the throttling-device in the annular test setup are illustrated in Fig. 1b), with respect to the phase-angles.

\subsubsection{Instrumentation}

The annular cascade was also equipped with a traversable stator blade moving in $y$-direction, allowing for areal surface pressure measurements on the $S S$ of the blade, as depicted in Fig. 2b. Here, a total of 24 static pressure ports were equidistantly distributed on the $S S$ of the blade profile. The static pressures from these locations were measured using differential pressure sensors [First Sensor: HDOM050] with a calibrated pressure range of -50 to 50 mbar. The static pressure distribution was measured at 99 span-wise locations.

Wake plane measurements were taken at $0.6 \cdot c$ downstream of the stators $T E$ (see Fig. 2a). In order to get a detailed wake pressure distribution and velocity profile, a miniature five-hole probe was traversed in a circumferential based polar grid, measuring mean and phase resolved values at each location. The grid covered one passage and had $N=20$ equidistant radial lines. On each radial line, grid points were distributed equidistantly along the circumference. The radial line at hub side held $M_{N 1}=10$ grid points, while the radial line at tip side held $M_{N 20}=20$ grid points.

\subsection{Actuator Design for Active Flow Control}

In the active flow control experiments a PJA system was used for the investigations. The actuator system consisted of a rectangular outlet orifice, measuring $h_{a c t} / c=$ 
0.0533 (slot height) and $d_{a c t} / c=0.001066$ (slot width) in relation to the chord length. The slot width in the annular cascade experiments was chosen slightly differently due to manufacturing constraints and measured $d_{a c t} / c=0.002133$. The outlet orifices had a blowing angle of $\omega=15^{\circ}$ relative to the passage end-wall and were perpendicular with respect to the blade's surface. The linear cascade was equipped with twelve actuators located on each passage end-wall (two actuators per passage) at $s / s_{\max }=$ 0.145 (relative suction surface coordinate). In the annular cascade setup, highly asymmetric flow separation phenomena govern the passage flow field. Accounting for this circumstance only the hub-sided end-wall was equipped with actuators for active flow control at a relative suction surface coordinate of $s / s_{\max }=0.129$. In the annular cascade, the mass flow used for the $A F C$ was controlled using mass flow meter [Festo-SFAB-1000] and a proportional directional valve [Festo-MPYE5-3/8-010-B]. In the linear cascade setup, a mass-flow controller [Bronkhorst-F203AV-1M0-ABD-55-V] was used to ensure for a constant actuation mass-flow rate. Furthermore, the pulsed blowing was realized by solenoid valves of the type Festo: MHE2-MS1H-3/2G-QS-4-K. The switching frequency, the actuators were operated with, is accounted for by the dimensionless frequency:

$$
S t_{a f c}=\frac{f_{a f c} \cdot c}{u_{1}} .
$$

\section{Results}

\subsection{Comparative Investigations on the Steady Flow Fields}

In this chapter, results of the undisturbed base flow are presented (no throttling device active). Since the airfoils are highly loaded, the passage flow field was dominated by strong secondary flow phenomena. Figure 3 shows two oil-flow visualizations of the investigated stator blades suction surfaces. In Fig. 3a the flow structures, measured in the linear cascade become evident [13]. A strikingly high symmetry in blade-height direction was detected.

A laminar separation bubble forms at approx. $s / s_{\max }=0.2$ in the $2 \mathrm{D}$ case. After the turbulent reattachment the flow separates again, due to the strong adverse pressure gradient and the enhancement of the secondary flow structures (corner separation), from $s / s_{\max }=0.6$ on. Further details on the steady flow field in the linear cascade are provided in Zander et al. [22] and Hecklau et al. [12].

The oil-flow visualization derived from the blade operated in the annular cascade is shown in Fig. 3b. The symmetric separation of the linear cascade cannot be found on the annular cascade blade, however, a massive corner separation occurs on the hub and expands up to $75 \%$ of the blade height $h$ at the TE. This hub-sided corner separation dominates the entire flow field. The tip region only shows a small area of this phenomenon with a spanwise extension of about $10 \% h$ at the TE. Between 


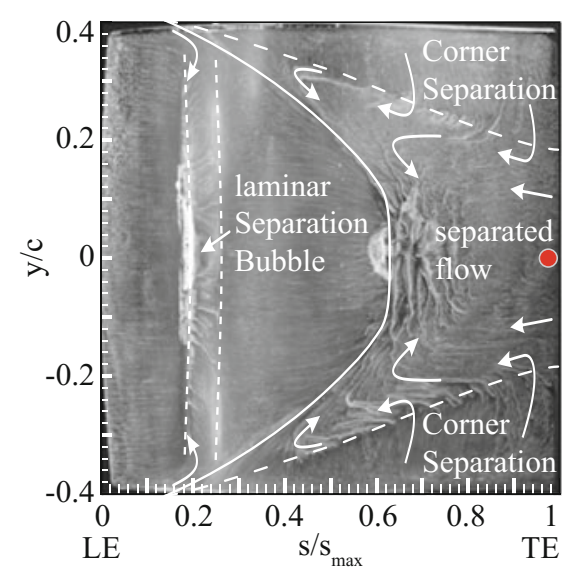

(a) 2D Cascade oil-flow visualization

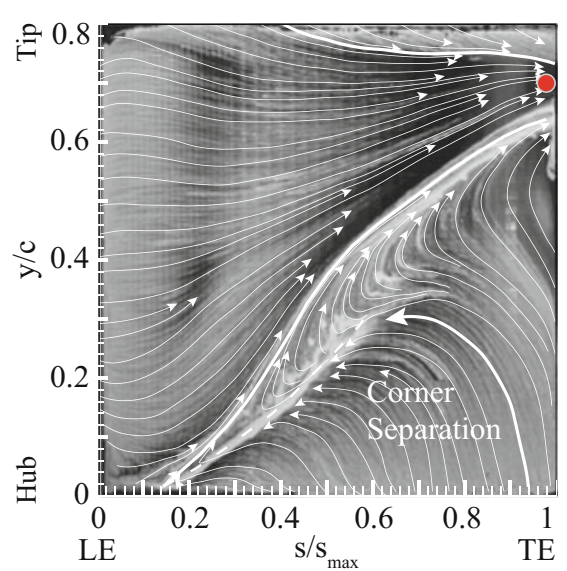

(b) 3D Cascade oil-flow visualization

Fig. 3 Comparison of oil-flow visualizations for both cascades

these corner separations a zone of attached flow is visible that cannot be seen in the linear cascade. The corner separation on the annular cascade blade starts at about $s / s_{\max }=0.15$ at the sidewall, expands along the blade span and blocks a huge part of the blade passage in the hub region. The flow is redirected because of this blockade and also accelerated due to the smaller relative flow passage. The stator passages expand in height-wise direction, which leads to a radial pressure gradient causing this increased growth of the hub-sided corner separation. Further investigations on that type of stator flow were performed by Beselt et al. [23].

\subsection{Comparative Investigations on the Unsteady Flow Fields}

In the following, the unsteady base flow without active flow control with respect to the two compressor stator test rigs (linear- and annular cascade) is discussed. In these cases, the throttling frequency was chosen such that the dimensionless frequency (STROUHAL-number $S t$ ) was constant in all cases and adjusted to $S t_{\text {throtling }}=0.03$ (linear cascade: $f_{\text {throtling }}=2 \mathrm{~Hz}$; annular cascade: $f_{\text {throttling }}=8 \mathrm{~Hz}$ ). The compressor stator performance was evaluated in terms of the Eqs. 2 and 3. The resulting values are depicted in Fig. 4. Here, the compressor stators were operated in the unsteady regime but time averaged data are shown in the figure. It was found that the linear cascade operated at lower total pressure losses with higher static pressure recoveries, compared to the annular cascade.

Figure 5 shows key results obtained from individual measurement campaigns. The figure subdivides into three columns. The plots arranged in the left column include information on the static pressure coefficient fluctuations, measured on the suction 
Fig. 4 Comparison of the compressor stator performances at STROUHAL number $S t_{\text {throttling }}=0.03$ evaluated for both cascades

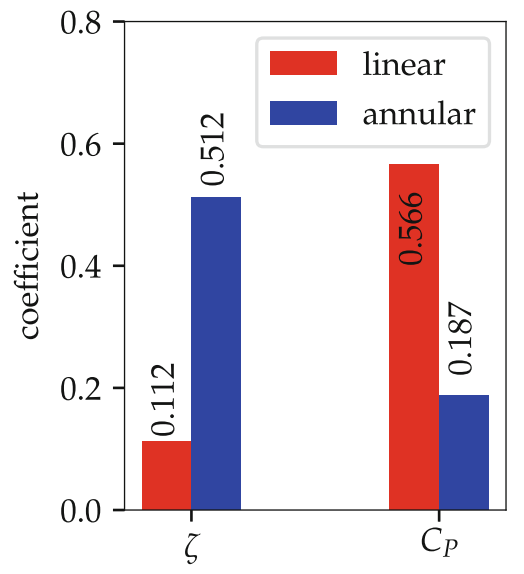

side of the measurement blade (between passage three and four; see Fig. 1a) on the linear cascade setup. The mid-column shows the corresponding data obtained from the annular cascades measurement blade. The data shown in the right column of Fig. 5 were taken from wake measurements and indicate the fluctuations in static pressure rise downstream of the stator passage. All data were phase-averaged and arranged row-wise in the figure. The sampling frequency was chosen to exceed the NYQUIST SHANNON sampling theorem with respect to the actuation frequency, which was higher than the throttling frequency, in order to gain sufficient fidelity. The corresponding phase-angles to each plot are found on the line plots ordinate. Here, the static pressure fluctuations on the suction surface of the blades were calculated by means of the REYNOLDS decomposition:

$$
c_{p}^{\prime}=c_{p}(\varphi)-\overline{c_{p}} .
$$

The phase-averaged static pressure rise through one passage, depicted by the lineplot, was divided by its mean value. The phase-angle, where the measurement passage (passage four in the linear cascade) of the cascades were fully blocked is marked in the line plot of Fig. 5 (phase-angle $\varphi=180^{\circ}$ ). In both cascades, the surface pressure distribution oscillated around a mean value. In the linear cascade the oscillation amplitude was $c_{p}{ }^{\prime}= \pm 0.1$. In the annular test setup, lower amplitudes occurred and static pressure fluctuations of up to $c_{p}{ }^{\prime}= \pm 0.05$ were measured. That value corresponds to approximately half the magnitude measured in the linear cascade flow. The oscillation in static pressure rise coefficient $C_{P} / \overline{C_{P}}$ through one passage reveal that the amplitudes measured in the annular cascade exceeded the values that originated from the linear cascade flow. The reason for that is twofold. The wake-measurement plane in the annular cascade was located at $0.6 \cdot c$ downstream the trailing edges, whereas the wake measurement plane in the linear cascade was located closer to the trailing edges, at $0.3 \cdot c$. It should be noted that in the annular cascade the wake measurement plane is affected earlier by the upstream moving 

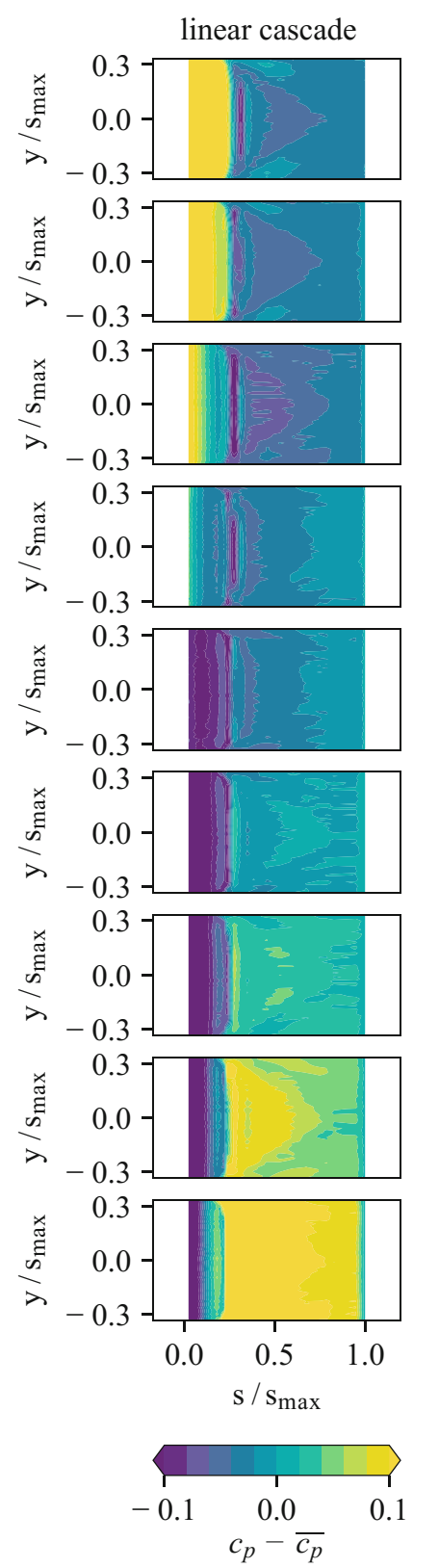
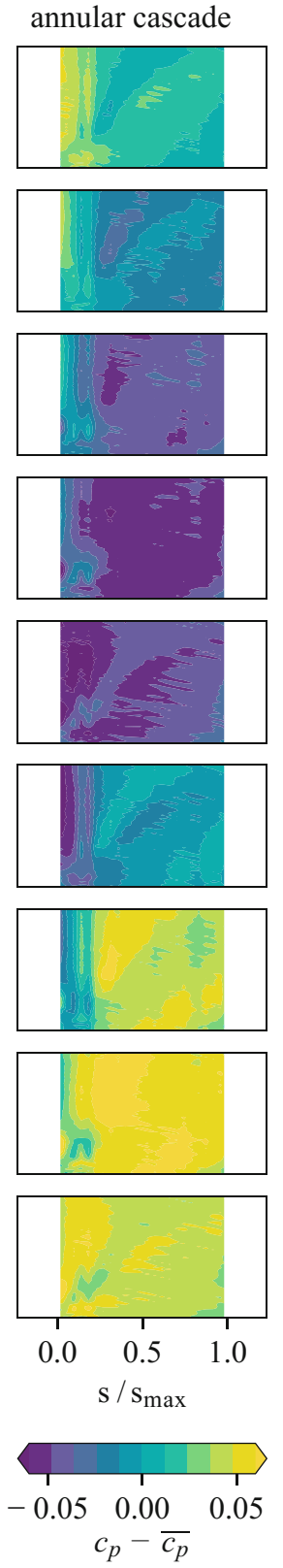

wake data
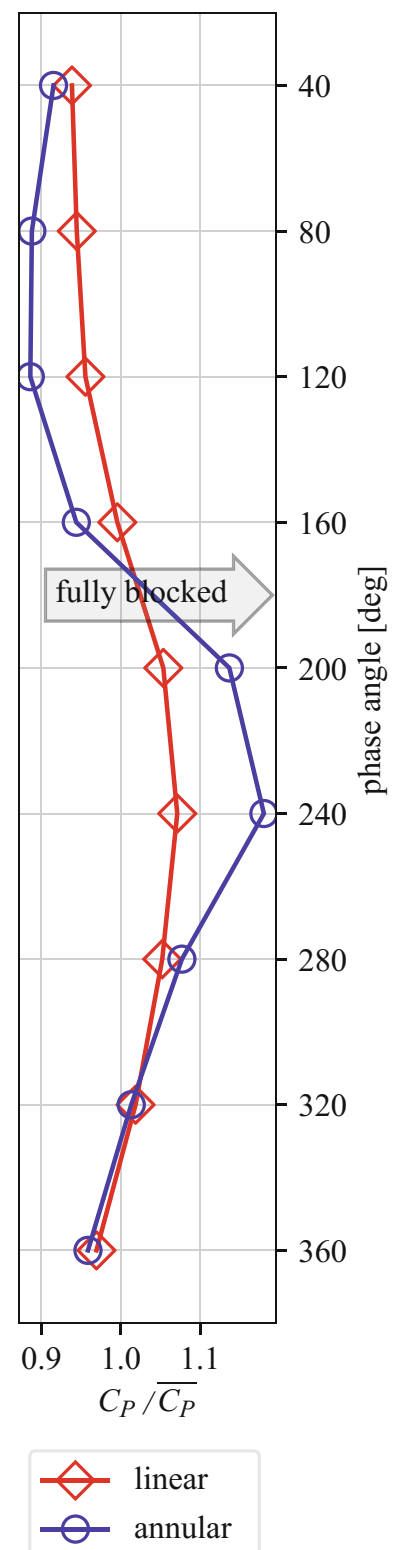

Fig. 5 Comparison of suction side static pressure distribution and wake pressure rise coefficient for both cascades at different throttling phase angles for unsteady base flow at $S t=0.03$ 
pressure wave caused by the throttling device, than in the linear cascade. This causes a decrease in measured pressure amplitude due to dampening effects. Secondly, the annular- and linear cascade flows indicated major differences in the passage flow field, thus leading to individual reactions of the passage flow, due to the unsteady operation of the two test rigs. However, the qualitative behavior of both cascades under unsteady loading conditions is comparable even though the two throttling devices are operated by different working principles (linear cascade: 21 periodically closing throttling flaps; annular cascade: rotating disk with two oppositely arranged paddles that choke the passages). Despite those differences, striking similarities in the data were found. The phase-angles with highest static pressure recovery measured in the $W M P$ were found at approximately $\varphi=240^{\circ}$. The highest static pressures on the stator blade suction sides occurred at $\varphi=320^{\circ}$ (annular cascade) and $\varphi=360^{\circ}$ (linear cascade). With respect to the highest values of the static pressure field on the suction surfaces of the blades and the maximum in static pressure rise through the measurement passage (measured in the WMP), a phase-angle shift in the same order of magnitude could be observed in both cascade setups. This shift equaled to approximately $\Delta \varphi=80^{\circ}$ to $100^{\circ}$ and is attributed to a certain inertia of fluid. The resulting phase-angle, with the minimum static pressure fluctuations on the blade, is in good correspondence among the two compressor test setups $\left(\varphi=160^{\circ}\right.$ to $\left.200^{\circ}\right)$. Due to the periodic throttling of the passages the operating point of one passage is constantly shifted (e.g. inflow angle variations that occur) [20].

\subsection{Comparison of Active Flow Control Results}

The general effect of using a side-wall actuator is that the passage is de-blocked by the actuation of the passage vortex that is reduced in size but not in strength [13, 17, 24].

As mentioned earlier, the linear cascade was equipped with two side-wall actuators per passage, whereas the annular cascade only uses one side-wall actuator to account for the non-symmetric flow structures. The increase of the trailing edge pressure was used to evaluate the impact of the actuation to the compressor stator flow field. The respective positions where $c_{p, T E, a f c}$ has been measured is marked with a red circle in Figure 3. These positions have been chosen because the maximum static pressure at the $T E$ is observed there, as shown in $[25,26]$. For the actuated case the maximum increase in pressure occurs at the same location. Figure 6 shows the increased timeaveraged static pressure recovery $\left(\Delta c_{p, T E, a f c}\right)$ of the stator blade on the ordinate. This parameter was calculated by the following equation:

$$
\Delta c_{p, T E, a f c}=c_{p, T E, a f c}-c_{p, T E, r e f}
$$

The reference trailing edge pressure coefficient is subtracted from the trailing edge pressure coefficient measured in a given actuation scenario. High trailing edge pressure recoveries indicate higher pressure recoveries throughout the whole passage, 


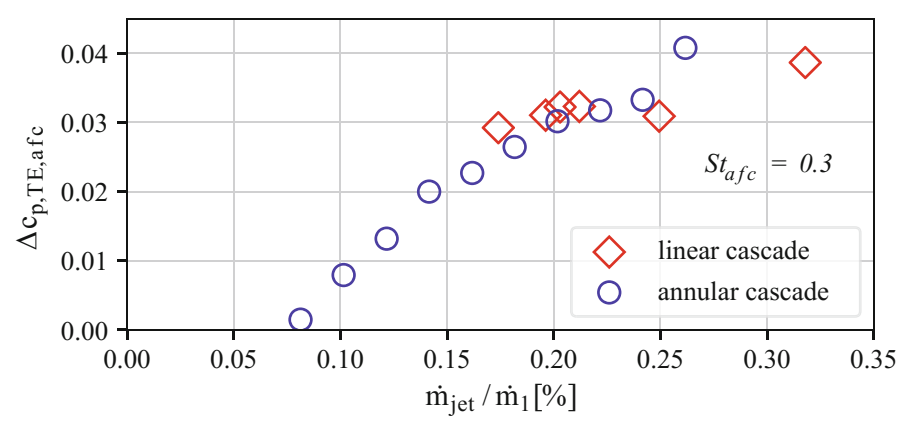

Fig. 6 Impact of $A F C$ to the trailing edge pressure coefficient in the linear and annular test setup

due to reduced passage blocking. The abscissa in Figure 6 shows the mass flow ratios of the active flow control. In both test setups, the dimensionless frequency of the actuation was kept constant at a STROUHAL number of $S t_{a f c}=0.3$. Here, the actuation frequency in the linear cascade case was $f_{a f c}=30 \mathrm{~Hz}$ and the annular cascade was actuated with a frequency of $f_{a f c}=81 \mathrm{~Hz}$.

In the discussed cases, the time-averaged trailing edge pressure recoveries, measured in the linear and the annular cascade, were in the same order of magnitude when a mass-flow ratio ranging from $\dot{m}_{\text {jet }} / \dot{m}_{1} \approx 0.15 \%$ to $\dot{m}_{\text {jet }} / \dot{m}_{1} \approx 0.32 \%$ was applied. By applying $\dot{m}_{\text {jet }} / \dot{m}_{1} \approx 0.2 \%$ of the passage mass-flow rate through the actuators a trailing edge pressure increase of $\Delta c_{p}=0.03$ was achievable in both configurations. Higher mass-flow rates lead to slightly increased trailing edge pressure recoveries. In the annular cascade case, the maximum investigated actuation mass-flow ratio was $\dot{m}_{j e t} / \dot{m}_{1} \approx 0.27 \%$, where the trailing edge pressure was increased by $\Delta c_{p}=0.04$. In the linear cascade case. the maximum investigated actuation mass-flow ratio of $\dot{m}_{j e t} / \dot{m}_{1} \approx 0.32 \%$ led to a comparable gain in trailing edge pressure recovery.

\section{Conclusion}

In this contribution, results obtained from two unsteady operated compressor stator cascades were shown. The unsteady outflow conditions were imposed by throttlingdevices that simulated the condition expected in a pulse detonation engine. In subproject B01 of the CRC1029, at TUB, two compressor test setups are operated (linear cascade and annular cascade), where such flows are investigated. The present paper contributes to a better understanding of the flow separation phenomena expected in a PDE and compares results from AFC experiments from such flow phenomena, measured in two different test setups. It was shown that the basic flow structures in the passage (e.g. corner separation) formed differently in both configurations. The impact of a periodic disturbance on the other hand was in good agreement for both investigated cases. The static pressure oscillations on the stator blading of the 
annular cascade reached half the magnitude, when compared to the linear cascade. Preliminary results with active flow control indicated a comparable effect of the pulsed jet actuation with respect to the increase of static pressure recovery for both investigated configurations. Increasing the time-averaged static pressure recovery by $\Delta c_{p, T E, a f c}=0.03$, with the use of $\dot{m}_{\text {jet }} / \dot{m}_{1} \approx 0.32 \%$ of the passage mass-flow rate, was feasible and identical for the investigated stator flows.

Acknowledgements The authors gratefully acknowledge support by the Deutsche Forschungsgemeinschaft (DFG) as part of collaborative research center SFB 1029 "Substantial efficiency increase in gas turbines through direct use of coupled unsteady combustion and flow dynamics" on project B01.

\section{References}

1. Stathopoulos P., Vinkeloe, J., Paschereit, C.O.: Thermodynamic evaluation of constant volume combustion for gas turbine power cycles. In: Proceedings of IGTC Tokyo: 11th International Gas Turbine Congress, November, 15th-20th, Tokyo, Japan, WePM1G.2 (2015)

2. Schmidt F., Staudacher S.: Generalized thermodynamic assessment of concepts for increasing the efficiency of civil aircraft propulsion systems. In: Proceedings of the ASME Turbo Expo 2015: Turbine Technical Conference and Exposition (GT2015), June, 15th-19th, Montreal, Canada, GT2015-42447 (2015)

3. Rouser K.P., King P.I., Schauer F.R., Sondergaard R., Hoke J.L. Goss, L.P.: Time-resolved flow properties in a turbine driven by pulsed detonations. J. Propuls. Power 30(6), 1528-1536 (2014)

4. Lu J., Zheng L., Wang Z., Peng C., Chen X.: Operating characteristics and propagation of backpressure waves in a multi-tube two-phase valveless air-breathing pulse detonation combustor. Exp. Therm. Fluid Sci. 61, 12-23 (2015)

5. Fernelius M.H., Gorrell S.E.: Predicting efficiency of a turbine driven by pulsing flow. In: Proceedings of the ASME Turbo Expo 2017: Turbine Technical Conference and Exposition (GT2017), June, 26th-30th, Charlotte, USA, GT2017-63490 (2017)

6. Staats M., Nitsche W.: Active control of the corner separation on a highly loaded compressor cascade with periodic non-steady boundary conditions by means of fluidic actuators. In: Proceedings of the ASME Turbo Expo 2015: Turbine Technical Conference and Exposition (GT2015), June, 15th-19th, Montreal, Canada, GT2015-42161 (2015)

7. Cumpsty N.A.: Compressor Aerodynamics, reprint ed. w/new preface, introduction and updated bibliography ed. Krieger Publishing Company, Malabar, USA (2004)

8. Wei M., Xavier O., Lipeng L., Francis L.: Intermittent corner separation in a linear compressor cascade. Exp. Fluids 54(6), 25 (2013)

9. Gbadebo, S.A., Cumpsty, N.A., Hynes, T.P.: Three-dimensional separations in axial compressors. J. Turbomach. 127(2), 331-339 (2005)

10. Peacock R.E.: Boundary-layer suction to eliminate corner separation in cascades of aerofoils. Technical report, Ministry of Defense, Aeronautical Research Council, Her Majesty's Stationery Office. Reports and Memoranda No. 3663 (1965)

11. Gbadebo, S.A., Cumpsty, N.A., Hynes, T.P.: Control of three-dimensional separations in axial compressors by tailored boundary layer suction. J. Turbomach. 130(1), 011004 (2008)

12. Hecklau, M., Wiederhold, O., Zander, V., King, R., Nitsche, W., Huppertz, A., Swoboda, M.: Active separation control with pulsed jets in a critically loaded compressor cascade. AIAA J. 49(8), 1729-1739 (2011) 
13. Zander, V., Hecklau, M., Nitsche, W., Huppertz, A., Swoboda, M.: Active flow control by means of synthetic jets on a highly loaded compressor cascade. Proc. Inst. Mech. Eng. Part A J. Power Energy 225(7), 897-908 (2011)

14. Wang, X., Zhao, X., Li, Y., Wu, Y., Zhao, Q.: Effects of plasma aerodynamic actuation on corner separation in a highly loaded compressor cascade. Plasma Sci. Technol. 16(3), 244-250 (2014)

15. Seifert A.: Evaluation criteria and performance comparison of actuators for bluff-body flow control. In: Proceedings of the 32nd AIAA Aviation Forum: Applied Aerodynamics Conference, June, 16th-20th, Atlanta, USA, AIAA 2014-2400 (2014)

16. Hecklau M., Zander V., Peltzer I., Nitsche W., Huppertz A., Swoboda M.: Experimental afc approaches on a highly loaded compressor cascade. In: King, R. (ed.) Active Flow Control II. Notes on Numerical and Fluid Dynamics, vol. 108, pp. 171-186. Springer (2010)

17. Staats M., Nitsche W.: Experimental investigations on the efficiency of active flow control in a compressor cascade with periodic non-steady outflow conditions. In: Proceedings of the ASME Turbo Expo 2017: Turbine Technical Conference and Exposition (GT2017), June, 26th-30th, Charlotte, USA, GT2017-63246 (2017)

18. Steinberg S.J., Staats M., Nitsche W., King R.: Comparison of conventional and repetitive MPC with application to a periodically disturbed compressor stator vane flow. In: Proceedings of the IFAC World Congress: The 20th World Congress of the International Federation of Automatic Control, July, 9th-14th, Toulouse, France, vol. 50(1), pp. 11107-11112 (2015)

19. Steinberg S.J., King R., Staats M., Nitsche W.: Constrained repetitive model predictive control applied to an unsteady compressor stator vane flow. In: Proceedings of the ASME Turbo Expo 2016: Turbine Technical Conference and Exposition (GT2016), June, 13th-17th, Seoul, South Korea, GT2016-56002, p. V02AT37A001 (2016)

20. Staats M., Nitsche, W.: Active flow control on a non-steady operated compressor stator cascade by means of fluidic devices. In: Notes on Numerical Fluid Mechanics and Multidisciplinary Design, vol. 136, pp. 337-347 (2016)

21. Brück C., Tiedemann C., Peitsch, D.: Experimental investigations on highly loaded compressor airfoils with active flow control under non-steady flow conditions in a 3D-annular lowspeed cascade. In: Proceedings of the ASME Turbo Expo: Turbine Technical Conference and Exposition-2016, The American Society of Mechanical Engineers, p. V02AT37A027 (2016)

22. Zander V., Hecklau M., Nitsche W., Huppertz A., Swoboda M.: Experimentelle methoden zur charakterisierung der aktiven strömungskontrolle in einer hoch belasteten verdichterkaskade. Deutscher Luft- und Raumfahrt Kongress (DLRK2008-081322) (2008)

23. Beselt C., Eck M., Peitsch, D.: Three-dimensional flow field in highly loaded compressor cascade. J. Turbomach. 136(10), 101007 (2014)

24. Hecklau M.: Experimente zur aktiven Strömungsbeeinflussung in einer Verdichterkaskade mit pulsierenden Wandstrahlen: Zugl.: Berlin, Techn. Univ., Diss., 2012. Aerospace Engineering. mbv Mensch-und-Buch-Verl., Berlin (2012)

25. Staats M., Nitsche W., Peltzer, I.: Active flow control on a highly loaded compressor cascade with non-steady boundary conditions. In: King, R. (ed.) Active Flow and Combustion Control 2014. Notes on Numerical Fluid Mechanics and Multidisciplinary Design, vol. 127, pp. 23-37. Springer (2015)

26. Brück C., Mihalyovics J., Peitsch, D.: Experimental investigations on highly loaded compressor airfoils with different active flow control parameters under unsteady flow conditions. In: Proceedings of GPPS Montreal: Global Power and Propulsion Conference North America-2018, May 7th-9th, Montreal, Canada, GPPS-2018-0054 (2018) 